\title{
Improved Operating Crushing and Milling Equipment
}

\author{
Sergey V. Korneev*a, \\ Yaroslav V. Yarmovich ${ }^{\mathrm{a}}$ and Ruslan V. Buravkin ${ }^{\mathrm{b}}$ \\ ${ }^{a}$ Omsk State Technical University \\ 11 Mira Str., Omsk, 644050, Russia \\ ${ }^{b}$ «Surgutneftegas» LLC \\ 1 Grigoriya Kukuevitskogo Str., bld. 1, Surgut, 628415, Russia
}

Received 16.08.2017, received in revised form 18.09.2017, accepted 20.10.2017

This article addresses the problem of reducing costs in the operation of crushing and milling equipment associated with high consumption of lubricant, as the volume of lubrication systems of crushing and milling equipment can be up to $60 \mathrm{~m}^{3}$. The reasons of rejection of the lubricant in the lubrication system of crushing and milling equipment, as well as to define the criteria of a limiting condition of the lubricant. The possibility of use in the lubrication system of crushing and milling equipment purified used motor oils. The study found that the replacement of the lubricant on the actual condition will reduce costs in the operation of crushing and milling equipment.

Keywords: Industrial oils, quality indicators, changes in the properties, the replacement of industrial oils, acid number, kinematic viscosity, mechanical impurities.

Citation: Korneev S.V., Yarmovich Ya.V., Buravkin R.V. Improved operating crushing and milling equipment, J. Sib. Fed. Univ. Eng. technol., 2017, 10(7), 922-931. DOI: 10.17516/1999-494X-2017-10-7-922-931.

(C) Siberian Federal University. All rights reserved

* Corresponding author E-mail address:nhi@omgtu.ru 


\title{
Совершенствование эксплуатации
}

\section{дробильно-размольного оборудования}

\author{
С.В. Корнеев ${ }^{\mathrm{a}}$, Я.В. Ярмович ${ }^{\mathrm{a}}$, Р.В. Буравкин ${ }^{\sigma}$ \\ ${ }^{a}$ Омский государственный технический университет \\ Россия, 644050, Омск, ул. Мира, 11 \\ ${ }^{6} \mathrm{OАО} \mathrm{«Сургутнефртегаз»}$ \\ Россия, 628415, Сургут, ул. Григория Кукуевиикого, 1, к. 1
}

В данной статье рассматривается проблема сокращения затрат при эксплуатации дробильно-размольного оборудования, связанная с большим расходом смазочного материала, так как объем систем смазки дробильно-размольного оборудования может составлять до

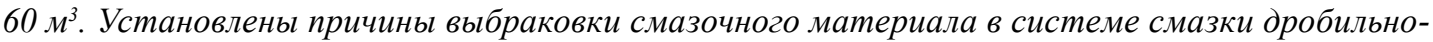
размольного оборудования, а также критерий предельного состояния смазочного материала. Рассмотрена возможность использования в системе смазки дробильно-размольного оборудования очищенных отработанных моторных масел. В результате исследования установлено, что замена смазочного материала по фактическому состоянию позволит сократить затраты при эксплуатации дробильно-размольного оборудования.

Ключевые слова: индустриальные масла, показатели качества, изменение свойств, замена индустриальных масел, кислотное число, кинематическая вязкость, механические примеси.

\section{Введение}

При обогащении руд полезных ископаемых основной операцией является их дробление, которое осуществляется с помощью конусных дробилок и шаровых, стержневых мельниц [1]. При эксплуатации этого оборудования используются индустриальные масла И-ГТ-А 100. Нужно отметить, что эти масла не содержат в своём составе присадок, а системы смазки этого оборудования весьма велики по объёму. Так, на Талнахской обогатительной фабрике ПАО «ГМК «Норильский никель» установлены емкости до $60 \mathrm{~m}^{3}$ для централизованной смазки узлов шаровых мельниц, а у шаровых мельниц - индивидуальные системы смазки с баками по 0,4 $\mathrm{m}^{3}$ [2]. Поэтому сокращение потребления индустриальных масел признано весьма актуальной задачей $[3,4]$.

В технической документации по эксплуатации данного оборудования нет четких указаний о периодичности замены смазочного материала. «Уралмашзавод», который выпускает шаровые мельницы и дробилки в инструкциях по эксплуатации, указывает, что замена масла должна производиться по мере его загрязнения. Такая неопределённость делает необходимым проведение дополнительных исследований по определению критериев предельного состояния индустриального масла применительно к конкретным узлам трения и условиям использования [5]. Эти работы особенно актуальны, так как многие предприятия отходят от плановой замены масел к замене по фактическому их состоянию.

\section{Определение критерия предельного состояния} для масла в системе смазки ДРО

Для анализа факторов, влияющих на работоспособность масла в системе смазки дробильноразмольного оборудования, были получены результаты испытаний масел на ПАО «ГМК «Но-

$$
-923-
$$


рильский никель», где с 1986 г. действует лаборатория оценки качества ГСМ. В лаборатории на все подконтрольное оборудование заведена картотека, в которой регистрируются результаты анализов масел. Проводятся исследования, предусматривающие определение следующих показателей индустриальных масел: вязкости, кислотного или щелочного числа, температуры вспышки, содержание механических примесей и воды.

Индустриальные масла общего назначения в своем составе не содержат присадок, поэтому выбраковка этих масел по изменению содержания присадок (в отличие от моторных масел) не проводится [6, 7].

Ниже представленны данные изменения физико-химических свойств индустриальных масел И-ГТ-А 100 [8] при эксплуатации в системах смазки ДРО, которое имеет коэффициент использования по времени, равный 0,66 , т. е. эксплуатируется в три смены с технологическими остановками и простоями в техническом обслуживании и ремонте. Мониторинг осуществлялся в течение 30 месяцев по разработанной программе. Сначала периодичность отбора проб составляла один месяц, затем установлена рациональная периодичность анализов один раз в квартал. Результаты мониторинга масел приведены в табл. 1.

Выбраковка масел в системах смазки ДРО в основном производится из-за значительного их загрязнения механическими примесями и водой, причем главной причиной ухудшения этих показателей являются особенности условий эксплуатации. Присутствие в масле механических примесей и воды существенно влияет на процессы изнашивания рабочих узлов в машине, особенно узлов с высокими контактными давлениями.

Процесс загрязнения масла зависит от многих факторов эксплуатации. В герметичных системах смазки прирост содержания механических примесей происходит постепенно с износом трущихся пар и легче поддается контролю. В негерметичных системах смазки, где возможно залповое попадание загрязнителя в масло, необходим более тщательный контроль прироста содержания механических примесей. Такой контроль возможен только при условии регулярного отбора проб масел для анализа масла.

При эксплуатации ДРО в опорных подшипниках скольжения происходит абразивный износ из-за не герметичности замкнутой системы смазки. Так, в систему смазки попадают частицы из окружающей среды и частицы обрабатываемого материала. Именно частицы обрабатываемого материала интенсивнее всего влияют на износ пар трения опорных подшипников скольжения.

Большая часть загрязнения имеет неорганический характер, а органическая часть загрязнений составляет 15-20 \% от их общего количества. В неорганической части загрязнений присутствуют частицы очень высокой твердости, превышающей в несколько раз твердость применяемых конструкционных материалов, что способствует повышенному износу деталей.

Для выявления критерия предельного состояния был проведен ряд экспериментов. При испытании фиксировались износ, температура в околоконтактной зоне и момент трения. Ролик (вал) изготавливали из стали 45 и подвергали закалке. До и после испытания образцы материалов взвешивали на аналитических весах с погрешностью не более 0,1 мг. Температура в околоконтактной зоне фиксировалась при помощи термопары типа ТХК, измерялся также момент трения. Пара трения нагружалась до давления 6,5 МПа и испытывалась при скорости 
Таблица 1. Изменение основных показателей качества индустриального масла И-ГТ-А 100 в процессе эксплуатации ДРО

Table 1. Changes in the basic indices of industrial oil quality with kinematic viscosity at 40 degrees Celsius 100 during the operation of equipment for crushing stone materials

\begin{tabular}{|c|c|c|c|c|c|}
\hline $\begin{array}{c}\text { Наработка } \\
\text { масла в системе } \\
\text { смазки, мес }\end{array}$ & $\begin{array}{c}\text { Вязкость } \\
\mathrm{Mм}^{2} / \mathrm{c}\end{array}$ & $\begin{array}{c}\text { Кислотное } \\
\text { число мг КОН/Г }\end{array}$ & $\begin{array}{c}\text { Температура } \\
\text { вспышки в } \\
\text { открытом } \\
\text { тигле, }{ }^{\circ} \mathrm{C}\end{array}$ & $\begin{array}{c}\text { Содержание } \\
\text { механических } \\
\text { примесей, } \\
\text { \% масс. }\end{array}$ & $\begin{array}{c}\text { Содержание } \\
\text { воды, \% масс. }\end{array}$ \\
\hline \multicolumn{6}{|c|}{ Мельница шаровая МШР 3,2x2,8 } \\
\hline 4 & 39,76 & - & 212 & 0,012 & Отсутствует \\
\hline 5 & 41,96 & - & 222 & 0,026 & 1,4 \\
\hline 6 & 41,39 & 0,032 & 220 & 0,013 & Отсутствует \\
\hline 7 & 39,26 & 0,036 & 218 & Отсутствуют & Отсутствует \\
\hline 9 & 38,02 & 0,032 & 216 & 0,33 & Отсутствует \\
\hline 12 & 40,31 & 0,103 & 216 & 0,025 & Отсутствует \\
\hline 13 & 39,84 & 0,0034 & 220 & 0,026 & Отсутствует \\
\hline 15 & 39,07 & 0,0024 & 212 & 0,09 & Отсутствует \\
\hline 18 & 39,17 & 0,01 & 210 & 0,028 & Отсутствует \\
\hline 22 & 40,88 & 0,03 & 210 & 0,029 & Отсутствует \\
\hline 24 & 42,97 & 0,09 & 208 & Отсутствуют & Отсутствует \\
\hline 30 & 45,0 & 0,02 & 200 & 0,08 & Отсутствует \\
\hline \multicolumn{6}{|c|}{ Дробилка конусная КСД 2200} \\
\hline 2 & 41,46 & - & 204 & 0,06 & 0,06 \\
\hline 3 & 45,83 & 0,121 & 224 & 0,015 & 0,04 \\
\hline 4 & 42,79 & 0,145 & 202 & 0,024 & Следы \\
\hline 5 & 41,65 & 0,134 & 208 & 0,011 & 0,25 \\
\hline 6 & 42,04 & 0,109 & 204 & 0,29 & Отсутствует \\
\hline 8 & 42,23 & 0,135 & 210 & 0,22 & Отсутствует \\
\hline 9 & 41,78 & 0,072 & 204 & 0,27 & Отсутствует \\
\hline 10 & 42,63 & 0,21 & 204 & 0,121 & 0,1 \\
\hline 11 & 38,66 & 0,014 & 206212 & 0,04 & Отсутствует \\
\hline 13 & 44,58 & 0,024 & 206 & 2,62 & 8,0 \\
\hline \multicolumn{6}{|c|}{ Произведен долив и очистка масла } \\
\hline 16 & 41,06 & 0,021 & 208 & 0,278 & 0,12 \\
\hline 19 & 44,82 & 0,038 & 212 & 0,097 & 0,12 \\
\hline 22 & 45,89 & 0,04 & 208 & 0,227 & Отсутствует \\
\hline 27 & 48,55 & 0,015 & 210 & 0,933 & Отсутствует \\
\hline
\end{tabular}

скольжения 1,64 м/с в течение 0,33 ч на каждой концентрации загрязнения с различной крепостью обрабатываемого сырья.

По полученным результатам испытаний построены графики зависимости износа пары трения, момента трения и температуры от процентного содержания механических примесей в образцах (рис. 1-3). 


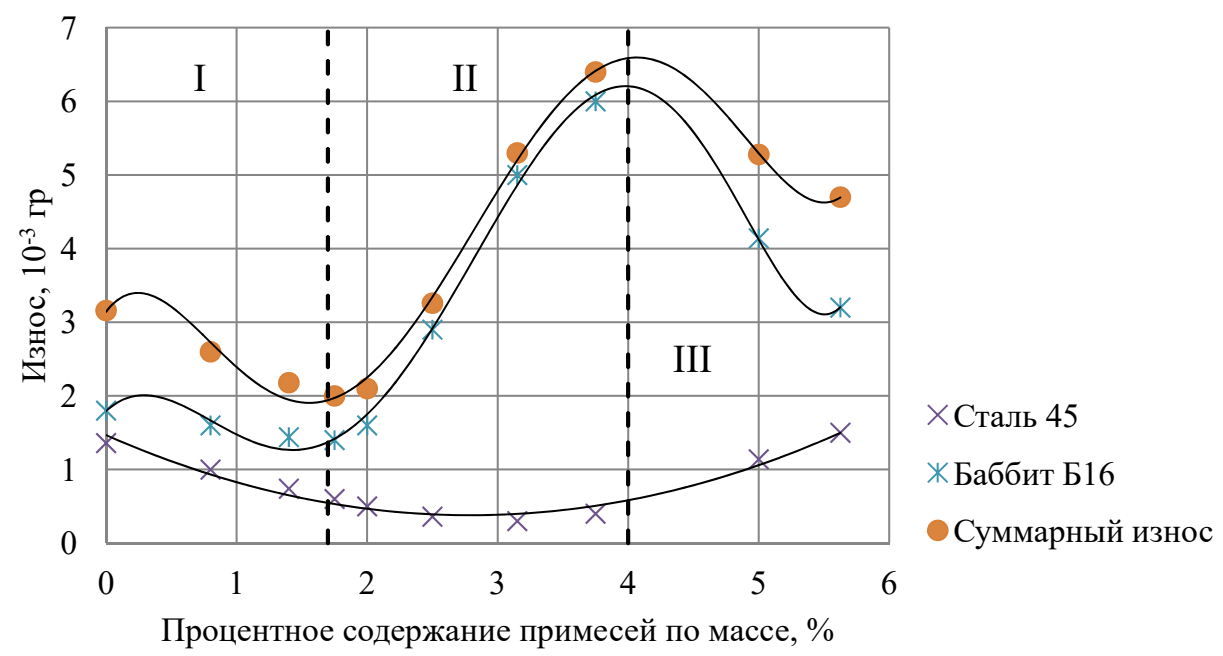

Рис. 1. Зависимость износа вала (сталь 45), вкладыша (баббит Б16) и суммарный износ от загрязненности масла И-ГТ-А 100

Fig. 1. Dependence of shaft wear (steel 45), liner (babbitt B16) and total wear from contamination of industrial oil with kinematic viscosity at 40 degrees Celsius 100

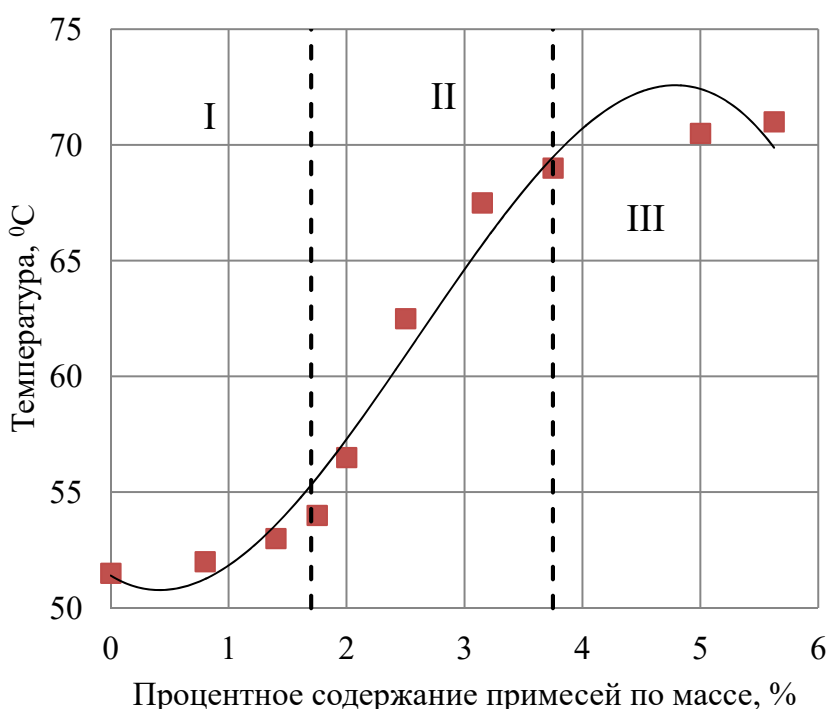

Рис. 2. Зависимость температуры в околоконтактной зоне при установившемся режиме трения от загрязненности масла И-ГТ-А 100

Fig. 2. Dependence of temperature in the near-contact zone under the steady-state friction regime from contamination of industrial oil with kinematic viscosity at 40 degrees Celsius 100

По мере увеличения содержания механических примесей в масле от 0 до 1,75 \% наблюдается относительно небольшой износ пары трения: это связано с тем, что незначительное внедрение абразива в поверхность баббита усиливает его, но эта концентрация не вызывает износ вала. Также наблюдается плавное повышение температуры, увеличение момента трения в установившемся режиме и некоторое снижение в пусковом. 


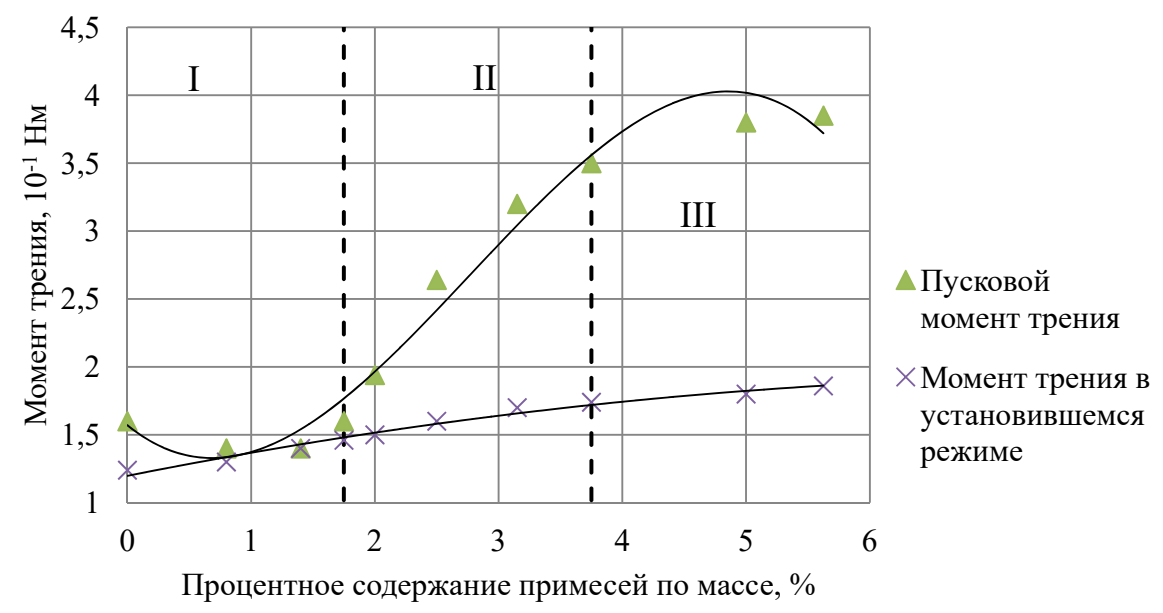

Рис. 3. Зависимость момента трения в установившемся режиме и пускового момента трения от загрязненности масла И-ГТ-А 100

Fig. 3. Dependence of the frictional moment in the steady state and the frictional starting torque on the contamination of industrial oil with kinematic viscosity at 40 degrees Celsius 100

При содержании механических примесей в масле от 1,75 до 3,5 \% отмечается увеличение температуры, момента трения и пускового момента. По-видимому, эти концентрации соответствуют ускоренному разрушению поверхности вкладыша. При дальнейшем росте содержания механических примесей в масле (более 3,5 \%) внедрение абразива в баббит делает его поверхность более твердой и несколько снижает износ, но это вызывает повышение износа ролика. При этом мало изменяется температура в околоконтактной зоне и момент трения в установившемся режиме, а также пусковой момент.

Из сказанного следует, что для обеспечения большего ресурса узлов трения ДРО необходимо ограничивать содержание механических примесей в масле уровнем, при котором не развивается процесс закрепления абразива на поверхности антифрикционного материала.

Известно, что разные по составу примеси неоднозначно влияют на износ пар трения не только в узлах ДРО. Так, для условий Средней Азии уровень механических примесей в маслах, циркулирующих в системах смазки ДРО, не должен превышать 1,2 \% (из-за большей абразивности горных пород). Температура $55{ }^{\circ} \mathrm{C}$ в околоконтактной зоне достигается уже при этом уровне загрязнений. Этот пример подтверждает, что при определении критериев состояния масла местные условия играют весьма важную роль.

Испытания проб масел, проведенные по описанной выше методике, для обрабатываемого сырья с различным коэффициентом крепости по шкале профессора М.М. Протодьяконова позволили выявить зависимость критерия предельного состояния от абразивных свойств механических примесей (рис. 4).

Для обеспечения работоспособного состояния системы смазки дробильно-размольного оборудования необходимо обеспечить содержание механических примесей на заданном уровне, что в свою очередь можно осуществить заменой или очисткой смазочного материала. При этом периодичность замены смазочного материала должна быть обоснована, чтобы

$$
-927-
$$




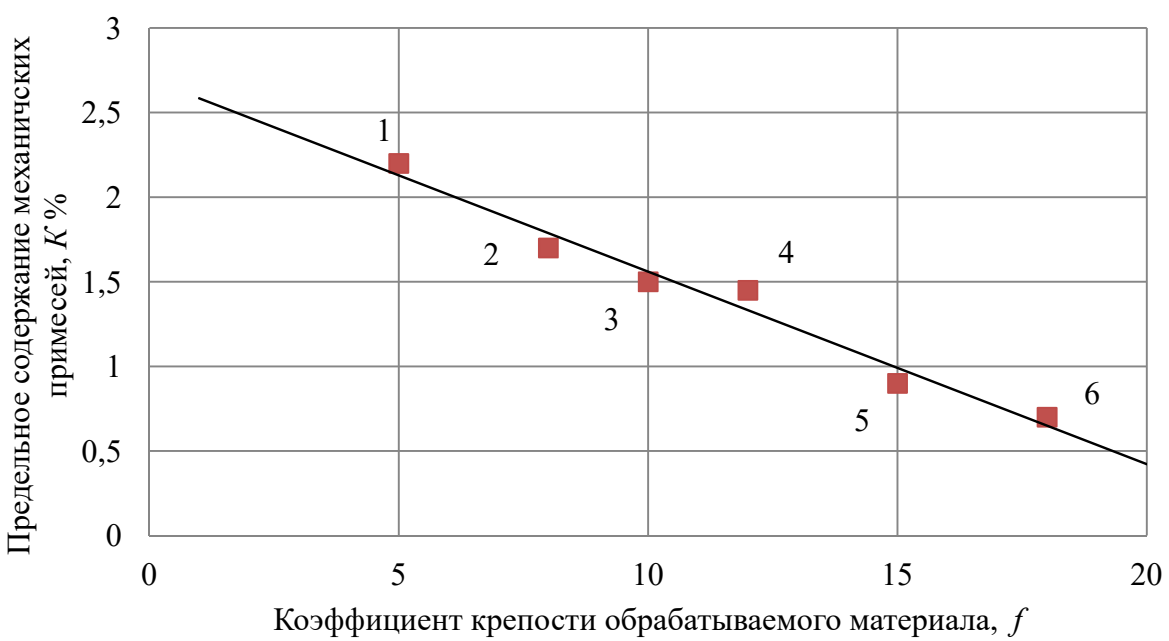

Рис. 4. Зависимость предельной концентрации механических примесей от крепости обрабатываемого материала по шкале М.М. Протодьяконова $1-2,2 \%(f=5) ; 2-1,75 \%(f=8) ; 3-1,5 \%(f=10) ; 4-1,45 \%$ $(f=12) ; 5-0,9 \%(f=15) ; 6-0,7 \%(f=18)$

Fig. 4. Dependence of the limiting concentration of mechanical impurities on the strength of the treated material on the scale of Professor MM Protodyakonov $1-2.2 \%(f=5) ; 2-1.75 \%(f=8) ; 3-1.5 \%$ ( $f=10) ; 4-1.45 \%$ $(\mathrm{f}=12) ; 5-0.9 \%(\mathrm{f}=15) ; 6-0.7 \%(\mathrm{f}=18)$

не допустить чрезмерных расходов на обслуживание и затрат от простоя оборудования в ремонте.

В соответствии с ГОСТ 21046-86 возможно использование очищенных отработанных моторных масел в качестве рабочей жидкости для ДРО. Для подтверждения данной возможности были проведены испытания на машине трения МИ-1М.

В качестве смазочного материала использовалось свежее масло И-Г-А 100 и смесь очищенных моторных масел M-10-B2, M-8-B2, М-10-Г2К. Износ материала изучали по схеме вал - частичный вкладыш. При данном испытании фиксировался лишь износ образцов, который фиксировался взвешиванием образцов материала до и после испытания на аналитических весах с погрешностью не более 0,1 мг. Пара трения нагружалась до давления 6,5 МПа и испытывалась при скорости скольжения 1,64 м/с в течение 0,33 ч.

Пробы смесей моторных масел очищались методами центрифугирования и отстоя до чистоты 11-12 классов по ГОСТ 17216-2001, после чего использовались для испытания. Все результаты испытаний сведены в табл. 2.

По средним значениям износа пары трения, была построена гистограмма (рис. 5).

Противоизносные свойства очищенных отработанных моторных масел М-10-B2, М-8-B2, М-10-Г2К лучше свойств свежего индустриального И-Г-А 100 из-за наличия в них остатков присадок, в том числе и противоизносных, которые не сработались в процессе эксплуатации двигателей внутреннего сгорания. Кроме того, в этих маслах присутствует мелкодисперсная сажа от продуктов неполного сгорания топлива, которая при трении является противозадирной присадкой, аналогичной графиту, что способствует улучшению противоизносных свойств, а также объясняет черный цвет отработанных моторных масел. 
Таблица 2. Результаты испытания подшипника скольжения при работе на очищенных отработанных моторных маслах М-10-В2, М-8-B2, М-10-Г2К и свежем индустриальном масле И-Г-А 100

Table 2. Test results for a plain bearing when working on cleaned engine oils with a kinematic viscosity of 8-10 at 100 degrees Celsius and fresh industrial industrial oil with kinematic viscosity at 40 degrees Celsius 100

\begin{tabular}{|c|c|c|c|c|}
\hline № опыта & Марка масла & $\begin{array}{c}\text { Начальная масса } \\
\text { подшипника, г }\end{array}$ & $\begin{array}{c}\text { Масса подшипника } \\
\text { после опыта, г }\end{array}$ & Износ подшипника, г \\
\hline 1 & \multirow{4}{*}{$\begin{array}{c}\text { Смесь моторных } \\
\text { масел }\end{array}$} & 95,2612 & 95,2606 & 0,0006 \\
\hline 2 & & 95,5354 & 95,5349 & 0,0005 \\
\hline 3 & & 95,3569 & 95,3562 & 0,0007 \\
\hline 4 & & 95,4864 & 95,486 & 0,0004 \\
\hline 1 & \multirow{4}{*}{ И-ГТ-А 100} & 95,2448 & 95,2434 & 0,0014 \\
\hline 2 & & 95,5144 & 95,5134 & 0,001 \\
\hline 3 & & 95,3489 & 95,3478 & 0,0011 \\
\hline 4 & & 95,5238 & 95,5229 & 0,0009 \\
\hline
\end{tabular}

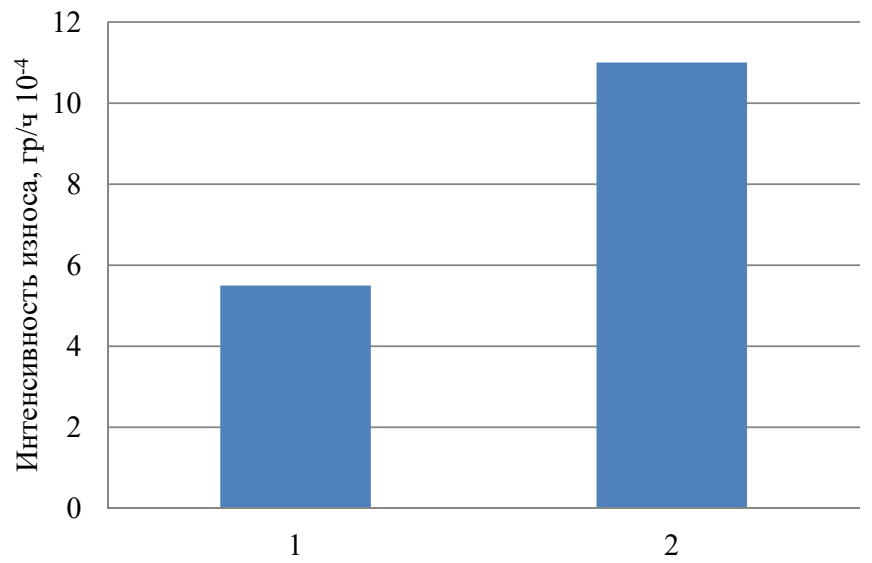

Рис. 5. Сравнительные испытания противоизносных свойств масел: 1 - смесь отработанных очищенных моторных масел М-10-В2, М-8-В2, М-10-Г2К; 2 - индустриальное масло И-ГТ-А 100

Fig. 5. Comparative tests of antiwear properties of oils: 1 - mixture of used purified motor oils with kinematic viscosity of 8-10 at 100 degrees Celsius; 2 - an industrial oil with a kinematic viscosity at 40 degrees Celsius 100

\section{Заключение}

Обобщив закономерности изменения характеристик масел в системах смазки ДРО, можно сделать вывод, что проведение анализов проб масел в полном объеме нецелесообразно. Достаточно определять три показателя: вязкость, наличие механических примесей и воды. Это поможет без ущерба для качества существенно сократить время, затрачиваемое на анализ каждой пробы масла. Кроме того, при ежемесячном проведении анализов установлено незначительное изменение характеристик масел, т. е. столь частый отбор проб нецелесообразен. По опыту эксплуатации систем смазки ДРО периодичность отбора проб масел скорректирована и принята 1 раз в 3 месяца.

Вязкость масла может определяться выборочно, так как меняется незначительно из-за отсутствия температурных воздействий.

$$
-929-
$$


Основной источник механических примесей в масле - это пыль от обрабатываемого сырья, поэтому определена зависимость критерия предельного состояния индустриального масла по содержанию механических примесей от крепости обрабатываемого сырья (по М.М. Протодьяконову). Для пар трения баббит Б-16 - сталь 45 критерий предельного состояния масла находится в пределах от 1 до 1,75 \% по массе.

Установлено, что смесь отработанных очищенных масел обладает лучшими противоизносными свойствами за счет наличия остатков присадок, которые не сработали во время эксплуатации, а также за счет присутствия в маслах мелкодисперсной сажи от продуктов неполного сгорания топлива, которая при трении является противозадирной присадкой.

Учитывая данные мониторинга состояния масел, можно сделать вывод, что такие показатели, как вода и содержание механических примесей, обязательны для контроля. При росте именно этих показателей требуется замена индустриальных масел в системах смазки дробильно-размольного оборудования или воздействия на масла для снижения содержания механических примесей и воды. Если удалять воду и механические примеси, можно значительно продлить их ресурс и сократить эксплуатационные затраты.

\section{Список литературы}

[1] Корнеев С.В., Лагунов В.Б., Данилов Л.И., Свечникава Ф.И., Каданцев А.В., Ножненко А.В. Рекомендации по применению смазочных материалов, оборудования и рациональному использованию смазочных материалов на предприятиях цьветной металлургии. М.: Металлургия, 1988. 192 с. [Korneev S.V., Lagunov V.B., Danilov L.I., Svechnikava F.I., Kadancev A.V., Nozhnenko A.V. Advice on applications of materials, equipment and rational utilization of lubricants on the non-ferrous metallurgy enterprises. Moscow, Metallurgiya, 1988, 192 p. (in Russian)]

[2] Корнеев С.В., Кулинич Н.Е., Мартынова Г.А. Оценка возможностей повторного использования отработанных масел в горно-обогатительных комбинатах АК «АЛРОСА» (ОАО). Экология и промышленность России, 2013, 10, 46-51 [Korneev S.V., Kulinich N.E., Martynova G.A. Evaluation of the ability to reuse of waste oils in the mining enterprises «ALROSA» (LLC), Ecology and Industry of Russia, 2013, 10, 46-51 (in Russian)]

[3] Корнеев С.В., Корниенко А.А., Ярмович Я.В. Обоснование использования отработанных масел в качестве базовых для приготовления пластичных смазок. Сборник научных трудов Sword, 2013, 12 (3), 34-37 [Korneev S.V., Kornienko A.A., Yarmovich Ya.V. Rationale for the use of waste oils as the base for the preparation of greases, Collection of scientific papers Sword, 2013, 12 (3), 34-37 (in Russian)]

[4] Корнеев С.В., Иванников А.А., Колунин А.В. Оценка возможностей рационального использования масел и утилизация отработанных. Вестник Сибирского отделения Академии военныхх наук, 2013, 23, 274-285 [Korneev S.V., Ivannikov A.A., Kolunin A.V. Assessment of possibilities of rational use and disposal of waste oils, Bulletin of the Siberian Branch of the Academy of Military Sciences, 2013, 23, 274-285 (in Russian)]

[5] Корнеев С.В., Смирнова Г.А., Финн Т.В. Пути экономии индустриальных масел при эксплуатации дробильно-размольного оборудования. Цветная металлургия, 1993, 1, 39-42 [Korneev S.V., Smirnova G.A., Finn T.V. Ways to save industrial oils in the operation of crushing and milling equipment, Non-ferrous metallurgy, 1993, 1, 39-42 (in Russian)]

$$
-930-
$$


[6] Чудиновских А.Л., Лашхи В.Л. Особенности формирования теории химмотологии моторных масел. Мир нефтепродуктов, 2014, 3, 38-43 [Chudinovskih A.L., Lashkhi V.L. Features of formation of the theory of motor oils Chemmotology, World of oil products, 2014, 3, 38-43 (in Russian)]

[7] Ярмолюк Б.М., Антонов В.Н., Юдина В.В., Любинин И.А., Шкарапута Л.Н. Современные моторные масла - проблемы, тенденции, перспективы. Мир нефтепродуктов, 2012, 12, 14 [Yarmolyuk B.M., Antonov V.N., Yudina V.V., Lyubinin I.A., Shkaraputa L.N. Modern engine oils issues, trends, prospects, World of oil products, 2012, 12, 14 (in Russian)]

[8] Нигматуллин Р.Г., Костенков Д.М., Пелецкий С.С., Хафизова А.Г., Нигматуллин И.Р., Муслухова Э.Л. Комплексный показатель работоспособности смазочного материала. Мир нефтепродуктов, 2012, 2, 27 [Nigmatullin R.G., Kostenkov D.M., Peleckij S.S., Hafizova A.G., Nigmatullin I.R., Musluhova E.L. An integrated component lubricant performance, World of oil products, 2012, 2, 27 (in Russian)] 